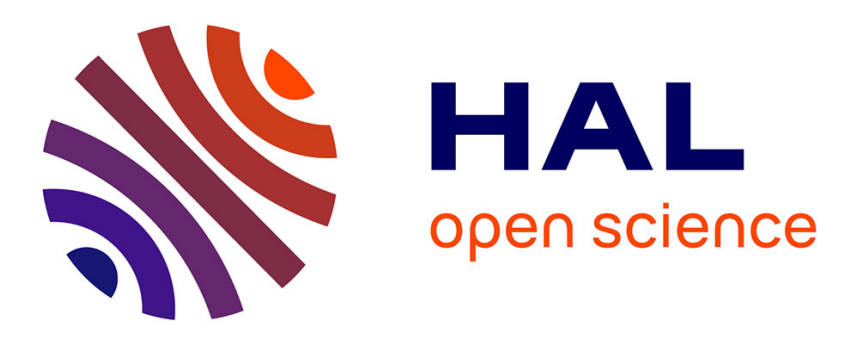

\title{
Photoluminescent Recognition of Strong Alcoholic Beverages with Carbon Nanoparticles
}

\author{
Ivan Ivanov, Alexander Zaderko, Vladimir Lysenko, Thierry Clopeau, \\ Vladyslav Lisnyak, Valeriy Skryshevsky
}

\section{- To cite this version:}

Ivan Ivanov, Alexander Zaderko, Vladimir Lysenko, Thierry Clopeau, Vladyslav Lisnyak, et al.. Photoluminescent Recognition of Strong Alcoholic Beverages with Carbon Nanoparticles. ACS Omega, 2021, 6 (29), pp.18802-18810. 10.1021/acsomega.1c01953 . hal-03325579

\section{HAL Id: hal-03325579 \\ https://hal.science/hal-03325579}

Submitted on 25 Aug 2021

HAL is a multi-disciplinary open access archive for the deposit and dissemination of scientific research documents, whether they are published or not. The documents may come from teaching and research institutions in France or abroad, or from public or private research centers.
L'archive ouverte pluridisciplinaire HAL, est destinée au dépôt et à la diffusion de documents scientifiques de niveau recherche, publiés ou non, émanant des établissements d'enseignement et de recherche français ou étrangers, des laboratoires publics ou privés. 


\section{Photoluminescent Recognition of Strong Alcoholic Beverages with Carbon Nanoparticles}

Ivan I. Ivanov, Alexander N. Zaderko, Vladimir Lysenko, Thierry Clopeau, Vladyslav V. Lisnyak, and Valeriy A. Skryshevsky*

Cite This: ACS Omega 2021, 6, 18802-18810

Read Online

ACCESS

Llll Metrics \& More

Article Recommendations

Supporting Information

ABSTRACT: A simple sensitive method for nonspecific recognition of armagnac, cognac, whiskey, and ethanol/water mixture was developed by using photoluminescence (PL) of carbon nanoparticles (NPs). The carbon NPs were synthesized from the mixture of urea and anhydrous citric acid, followed by few annealing processes to achieve the full effect by solvothermal carbonization. PL features of carbon NPs depend on the alcohol environments in which the NPs are dispersed. PL/PL excitation maps of the alcoholic beverages were mathematically treated, and a final principal component analysis diagram allows visualization of different clusters corresponding to each beverage. The optimal measurement conditions (concentration of NPs in colloidal solution and excitation wavelength) were defined to ensure a reliable recognition level.

\section{INTRODUCTION}

Nowadays, various expensive brands of outstanding prestigious alcoholic beverages are available in the world market, and this can provoke malevolent intentions for their potential adulteration or contamination by admixing of water, low-end grade alcohol, or some other inexpensive additives. ${ }^{1}$ For this reason, quality control of alcoholic beverages becomes imperative for regulating the alcohol market and for protecting the consumers' health. This requires the ability to distinguish any difference between the controlled alcoholic drinks. ${ }^{2}$

It should be noted that alcoholic beverages have a very complicated chemical composition. ${ }^{3}$ Several steps leading to the elaboration of a brandy give rise to complex tannins, aromas, and tastes, which result from specific volatile compositions that can be different depending on the types and brands of the alcohol beverage. Referencing literature, we can find various data: the great complexity of the composition of grape brandies with $139,,^{4} 227,5$ and $331^{6}$ identified compounds. In brandies, ethyl acetate is the major ester, with the concentration varying from 20 to $2000 \mathrm{mg} / \mathrm{L}^{7}$ The volatile composition of brandies is also characterized by high contents of low-molecular-weight ethyl esters and some phenols, aldehydes, and acetals. While aging in wooden casks, whiskey undergoes six consequent processes that contribute to its final flavor: extraction, evaporation, oxidation, concentration, filtration, and coloration. ${ }^{8}$ Extraction in particular results in whiskey acquiring many compounds, including aldehydes and organic acids such as vanillin, vanillic acid, and syringaldehyde. ${ }^{9}$ Considering that comprehensive analysis of the chemical composition is time-consuming and requires high-cost laboratory equipment, the creation of simple, efficient, and low-cost methods/devices to detect/ recognize alcoholic beverages is strongly requested.

For the analysis of ethanol and other components in alcoholic beverages, a variety of common analytical methods and sensitive reagents have been already developed. ${ }^{10-18}$ The used methods include gas chromatography, ${ }^{10}$ mass spectrometry, ${ }^{11} \mathrm{UV}$-vis-IR spectrometry, ${ }^{12}$ colorimetric analysis, ${ }^{13}$ application of electrical transducers ${ }^{14}$ and different biosensors, ${ }^{15}$ solid-phase microextraction, ${ }^{16}$ use of green fluorescent proteins, $^{17}$ and many others. ${ }^{18}$

Analytical approaches based on fluorescent/luminescent techniques have to be specifically remarked. They are extremely sensitive; their sensitivity reached the absolute limit of single molecules. They offer a very high spatial resolution that, by overcoming the light diffraction limit, has reached a molecular scale. They are also the fastest; their response develops on the scale of fluorescence lifetime and can be as short as $10^{-8}$ to $10^{-10} \mathrm{~s}$. Moreover, their greatest advantage is versatility. Fluorescence sensing can be provided in solid, liquid, and gas media and at all kinds of interfaces between these phases. This is because the fluorescence emitter and the detecting instrument are connected via light emission.

Received: April 12, 2021

Accepted: June 25, 2021

Published: July 12, 2021 


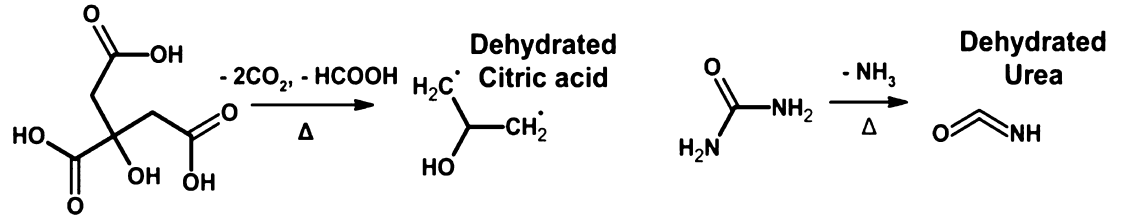<smiles>NC(=O)NC(=O)NC(=O)NC(=O)NC(=O)NC(N)=O</smiles>

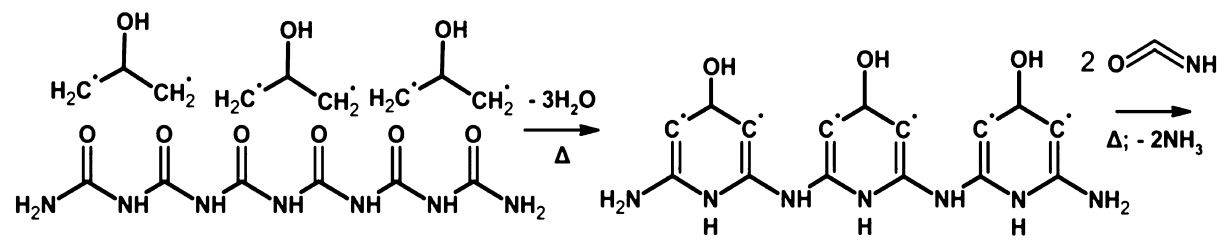

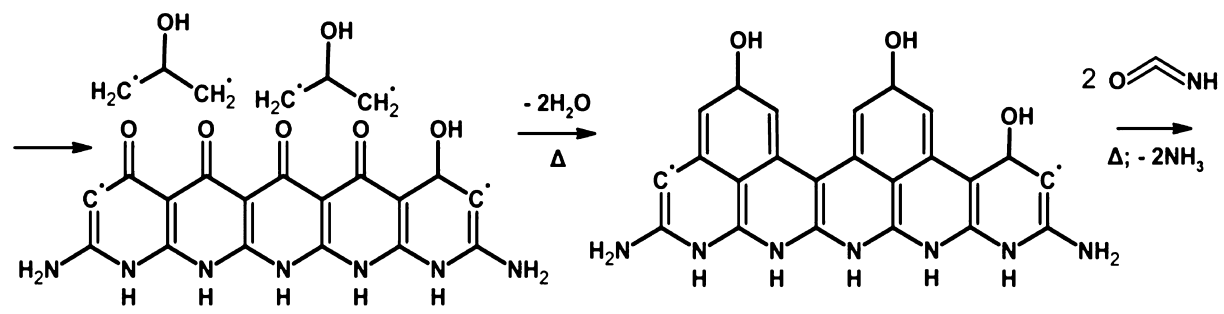

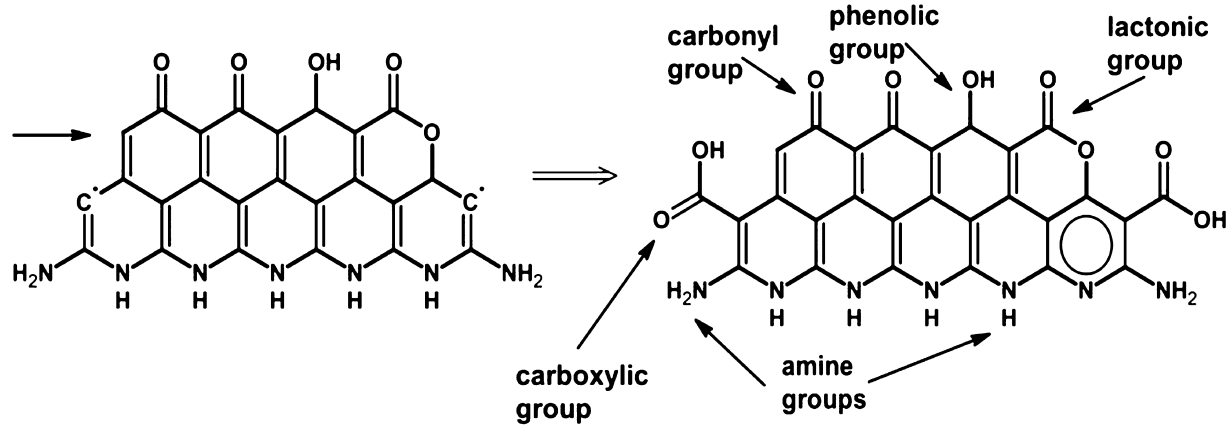

Figure 1. Possible thermochemical transformations producing carbon NPs. Growth mechanism of carbon NPs with increasing temperature and growth time.

Fluorescence detection can be made noninvasive and equally well suited for remote industrial control and for sensing different targets within the living cells. ${ }^{19}$ Various fluorescent materials have been designed and developed including organic dyes, quantum dots, metal-organic frameworks, and fluorescent proteins. ${ }^{19}$ For example, the luminescence of nanoparticles (NPs) was found to be sensitive to pesticides, ${ }^{20}$ antibiotics, $^{21}$ a change of $\mathrm{pH}$ solution during enzymesubstrate reaction, ${ }^{22}$ and other species.

Recently, carbon NPs have been given special attention due to their unique optical properties, good biocompatibility, low toxicity, high aqueous stability, and facile synthesis. ${ }^{23}$ Besides, they can be can be chemically modified after their synthesis with oxygen/nitrogen-based groups. ${ }^{24,25}$

In the present work, we consider a possibility to create simple photoluminescent sensitive colloids based on carbon NPs in order to distinguish various alcoholic beverages without the definition of their individual chemical compositions. Principal component analysis (PCA) method ${ }^{26,27}$ was used for the reduction of data dimension for further visualization and analysis of the analyte difference.

\section{RESULTS AND DISCUSSION}

In this paper, we consider the mechanism of carbonization of citric acid in the urea melt. Figure 1 schematizes the transformations and shows possible intermediates and products. We assumed that at the first stage of carbonization, heterocyclic nitrogen compounds are formed, for example, 4hydroxy- $1 H$-pyrrolo[3,4-c]pyridine-1,3,6 $(2 H, 5 H)$-trione ${ }^{28}$ or citrazinic acid. ${ }^{29}$ Both of them then can form polycondensed heterocyclic skeleton during thermal condensation. However, the mechanism of such condensation is not well known. At the first stage, we assume the forming polyuria from urea as the basis for the future carbon NPs. After that, the polyuria is attacked by hypothetical particles, which are products of complete loss of water and ammonia by citric acid and urea molecules. From the considering of the partial substrate carbonization, it is clear that the thermal treatment is not 


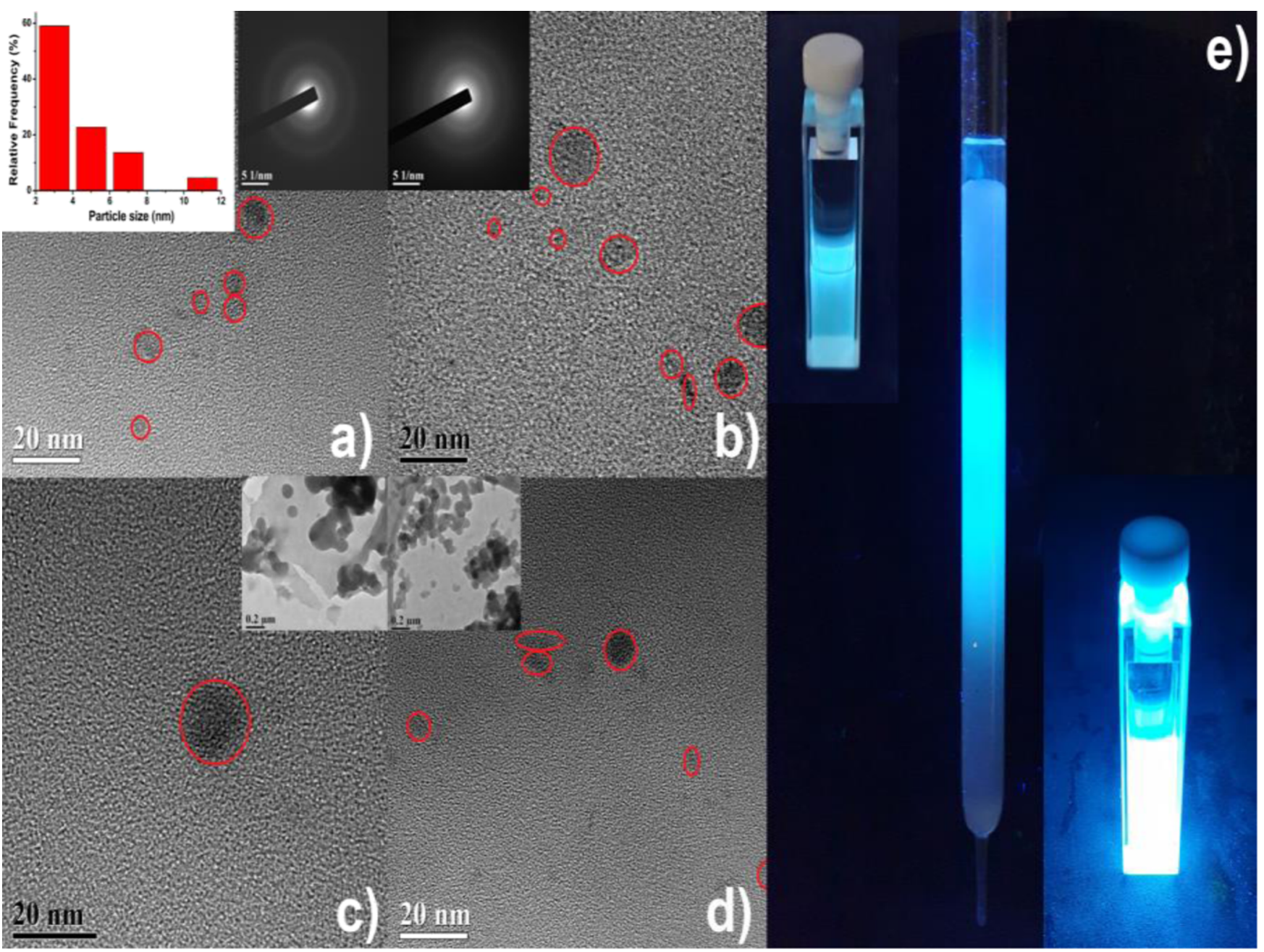

Figure 2. $(a-d)$ TEM images of carbon NPs. Insets in (a,b): SAED patterns and the histogram of particle size distribution from the captured carbon NPs. Insets in (c,d): aggregated carbon NPs. (e) Chromatographic column with carbon NPs and their alcohol solutions under UV excitation, under $365 \mathrm{~nm}$ radiation.

reduced to decarboxylation of citric acid. The elimination of carboxyl groups from citric acid, formally the elimination of $\mathrm{H}_{2} \mathrm{O}$ and $\mathrm{CO}+\mathrm{CO}_{2}$, causes the formation of stronger bonds in the thermal decomposition products. Decarboxylated citric acid is shown by particle (I), which is a hypothetical biradical of isopropanol. By eliminating ammonia, urea transforms into particle (II), which is a stable but highly reactive molecule of isocyanic acid. The intermediate products easily (like a puzzle) fold into carbon NPs with functional groups dispersed in the carbon-nitrogen plane and at the edges (see Figure 1). The formation of different groups is confirmed by the thermogravimetric analysis (TGA) of the end product (Figure S1, Supporting Information). In principle, a particle of any size can be folded using this approach. However, in the present case, the size of carbon NPs showed limited growth.

From the collected structural information about local binding environments, X-ray photoelectron spectroscopy (XPS) analysis showed that carbon, oxygen, and nitrogen copresented in the carbon NPs (Figure S2, Supporting Information). Both peak-split and fitting processes showed that the carbon core-level XP spectrum can be divided into several peaks with different energy intensities: the peaks at $284.5 \mathrm{eV}$ and $285.0 \mathrm{eV}$ indicate aliphatic carbons and aromatic carbons. The $\mathrm{C}-\mathrm{N}$ peak appears at $285.7 \mathrm{eV}$. Because of the oxygen content, the peak, which is a superposition of $\mathrm{C}=\mathrm{N}$ assigned to the imine groups with $\mathrm{C}-\mathrm{O}$ peaks related to phenol or ether carbons, is observed at around $286.6 \mathrm{eV}$. The characteristic peak at $288.2 \mathrm{eV}$ denotes carbonyl carbons $(\mathrm{C}=$ $\mathrm{O})$ and amide carbons $(\mathrm{C}-\mathrm{NH})$. The peak at $289.0 \mathrm{eV}$ is assigned to carboxyl carbons (COO). The high-resolution $\mathrm{O}$ 1s XP spectrum demonstrated the presence of oxygencontaining functional groups forming $\mathrm{C}=\mathrm{O}$ and $\mathrm{C}-\mathrm{O}-\mathrm{C}$ bonds with binding energies of 531.5 and $533.2 \mathrm{eV}$, respectively. The high-resolution $\mathrm{N}$ 1s XP spectrum shows a peak at $399.7 \mathrm{eV}$. This peak is assigned as a combination of contributions of unreacted primary amino groups and imine groups that are formed. It is impossible to differentiate contributions from $\mathrm{C}-\mathrm{NH}_{2}$ and $\mathrm{C}=\mathrm{NH}$ peaks from the highresolution XP N 1s spectrum where both XPS peaks appear at close binding energies. ${ }^{1} \mathrm{H}$ NMR spectrum of the colloid solution of the carbon NPs showed the presence of heterocyclic aromatic moieties (Figure S3, Supporting Information).

To capture the transmission electron microscopy (TEM) images and purify the carbon NPs to be used for further studies, the precipitated sample was dissolved in alcohol alkalized with ammonia to prepare a $0.01 \mathrm{wt} \%$ solution. This solution was purified in a column packed with Millipore silica 


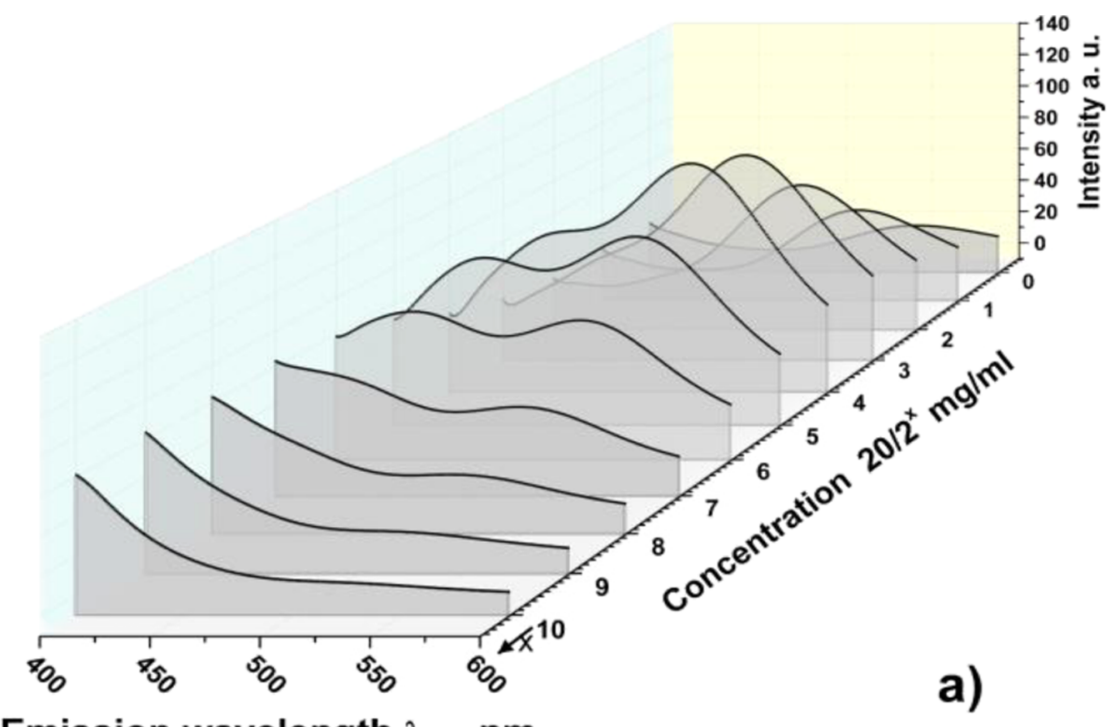

Emission wavelength $\lambda_{\text {em }}, \mathrm{nm}$

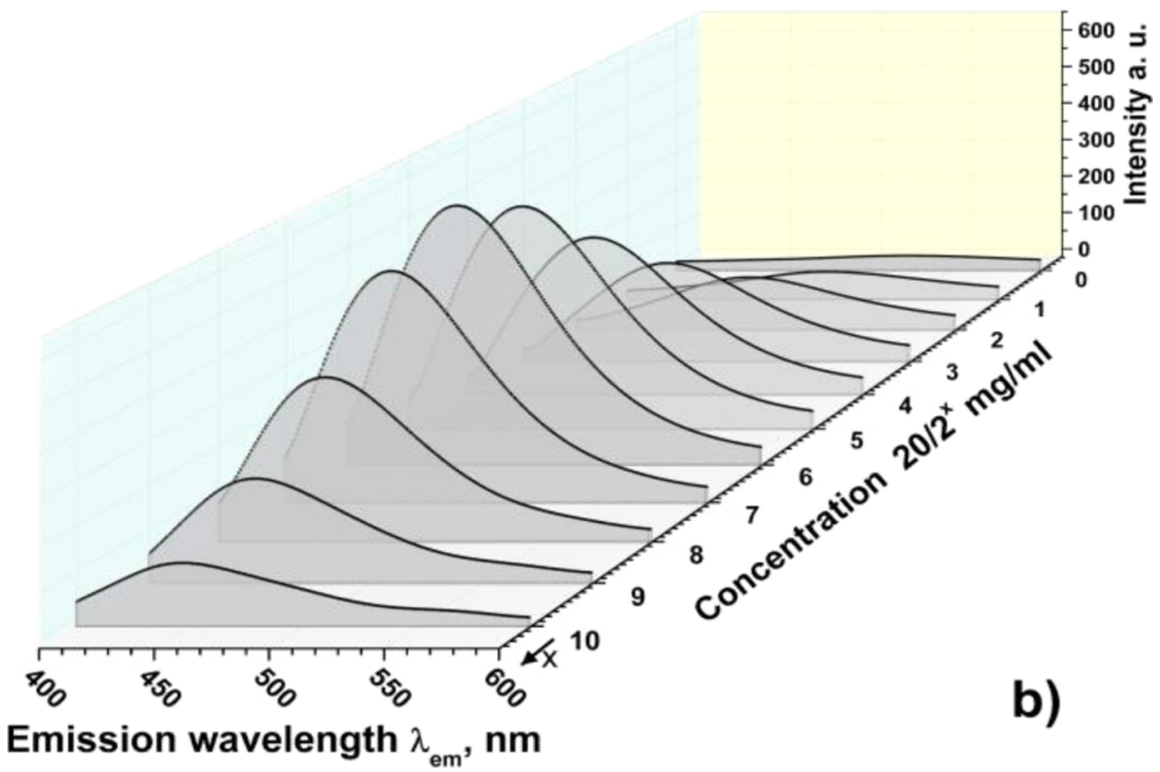

Figure 3. Intensity of emission spectra recorded at (a) $\lambda_{\mathrm{ex}}^{1}=285 \mathrm{~nm}$ and (b) $\lambda_{\mathrm{ex}}^{2}=355 \mathrm{~nm}$ against the concentration of carbon NPs.

gel 60 (0.063-0.200 mm mesh, Merck KGaA, 64271 Darmstadt, DE). In the course of column chromatography, one fraction, which glows blue-green under UV light, was found (Figure 2). TEM and selected area electron diffraction (SAED) images were registered for very diluted solutions of carbon NPs (to prevent aggregation); these images showed individual semicyclic carbon NPs about $2-8$ and $10-12 \mathrm{~nm}$ in width and about $0.5 \mathrm{~nm}$ in thickness, and those with a diameter of $3 \mathrm{~nm}$ prevailed (see histogram, which is taken over 50 particles, shown as Figure $2 \mathrm{a}$ inset). We assume that the carbon NPs have an average size below $20 \mathrm{~nm}$. Captured TEM images of amorphous carbon NPs show no events of characteristic patterns of the "graphite-like" ordering, ${ }^{30}$ and interlayer spacing and in-plane spacing are not clearly observed.

Fourier transform infrared attenuation total reflectance (FTIR ATR) confirmed the presence of many $\mathrm{O}$ - and $\mathrm{N}$ containing functional groups (Figure S4, Supporting Informa- tion). Spectral bands attributed to different modes of $\mathrm{C}-\mathrm{OH}$, $\mathrm{C}-\mathrm{O}$, and $\mathrm{C}=\mathrm{O}$ bonds in phenol, alcohol, and carboxylic groups are found. The $(\mathrm{C}=\mathrm{N})$ and $(\mathrm{C}=\mathrm{C})$ stretching vibrations were attributed to the aromatic rings of the carbon (N) skeleton. Besides, the spectral bands from the $\mathrm{C}-\mathrm{N}$ and $(-(\mathrm{C})-\mathrm{N}-\mathrm{H})$ bonds can be assigned to different amino groups. Raman spectrum showed a typical halo from amorphous carbon (Figure S5, Supporting Information).

Like many other kinds of conjugated $\pi$-electron systems, the solutions of carbon NPs act as chromophores and absorb light in the 200-550 $\mathrm{nm}$ region (Figure S6, Supporting Information). This region includes $\mathrm{n} \rightarrow \pi^{*}$ and $\pi \rightarrow \pi^{*}$ electron transitions referring to the conjugated carbonyl groups $(\mathrm{C}=\mathrm{C}-\mathrm{C}=\mathrm{O})$ and aromatic heterocyclic structures. The $\pi-\pi^{*}$ absorption located at $242 \mathrm{~nm}$ is very strong, presumably due to electron transitions in the carbonyl groups and because of $\pi-\pi^{*}$ electron transitions in the conjugated aromatic system of the heterocyclic skeleton, for which the intrinsic absorption 

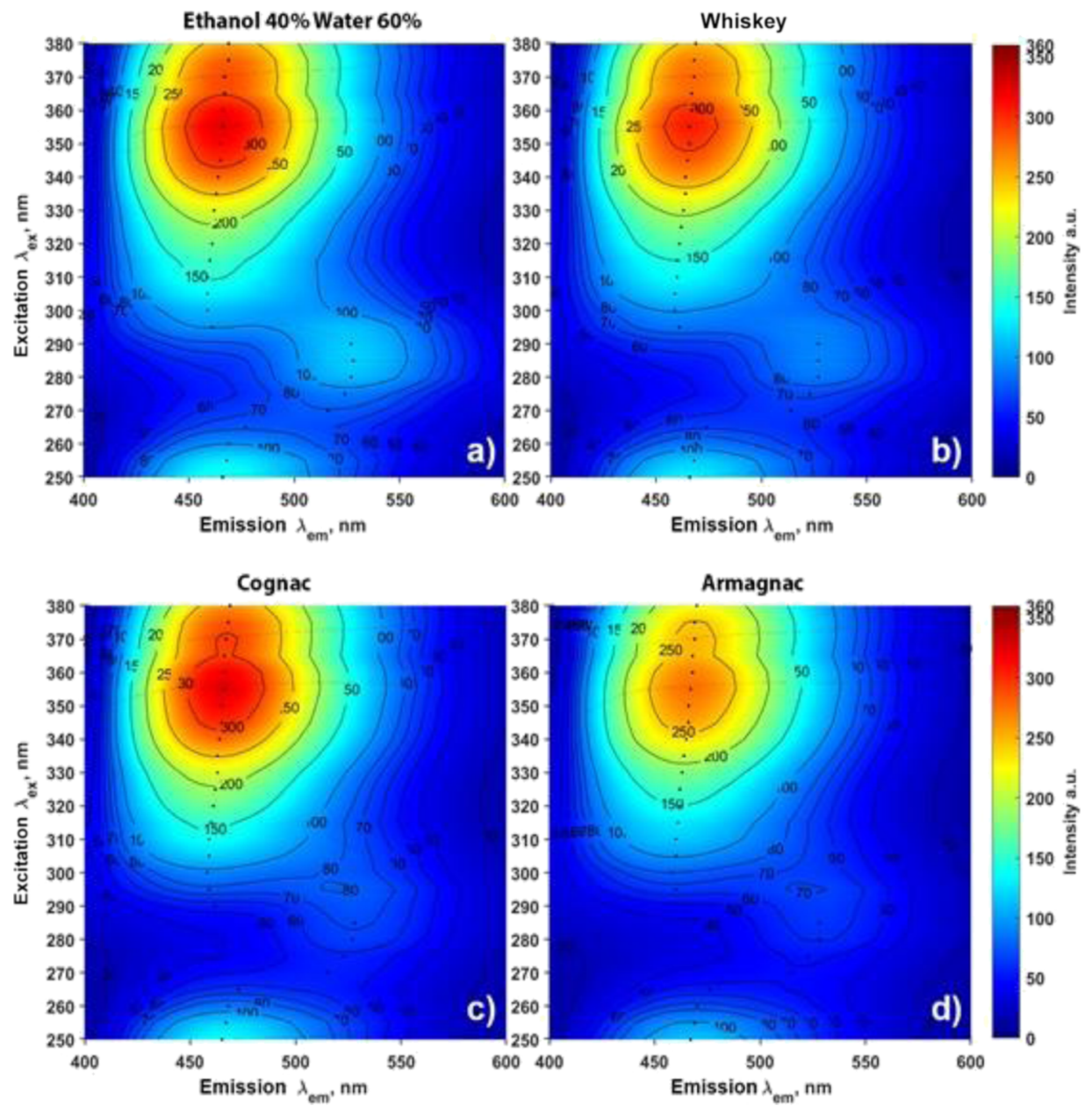

Figure 4. PL maps for the solution of carbon NPs $\left(c_{\mathrm{NP}}^{4}=20 / 2^{4} \mathrm{mg} / \mathrm{mL}\right)$ in the presence of analyte: (a) ethanol/water solution (40/60 vol), (b) whiskey, (c) cognac, and (d) armagnac.

bands centered at 357 and $450 \mathrm{~nm}$ are presented in the UVvis spectra.

Dependences of the intensity of photoluminescence (PL) emission spectra on excitation spectra for different concentrations $c_{\mathrm{NP}}^{x}=c_{\text {init }} / 2^{x}$ of carbon NPs were obtained for $c_{\text {init }}=20$ $\mathrm{mg} / \mathrm{mL}$ and $x=0,1, . ., 10$ (Figure S7, Supporting Information).

The recorded 3D PL maps allow distinguishing two excitation wavelengths at which emission spectra have maxima at $\lambda_{\mathrm{ex}}^{1}=285 \mathrm{~nm}$ and $\lambda_{\mathrm{ex}}^{2}=355 \mathrm{~nm}$ (Figure 3 ). With decreasing concentration of NPs, the position of the PL emission peak \#1 for $\lambda_{\mathrm{ex}}^{1}$ shifts from $\lambda_{\mathrm{em}}\left(\mathrm{c}_{\mathrm{NP}}^{0}\right)=553 \mathrm{~nm}$ to $\lambda_{\mathrm{em}}\left(\mathrm{c}_{\mathrm{NP}}^{9}\right)=517 \mathrm{~nm}$. The position of the PL emission peak \#2 for $\lambda_{\mathrm{ex}}^{2}$ shifts from $\lambda_{\text {em }}\left(c_{\mathrm{NP}}^{0}\right)=525 \mathrm{~nm}$ to $\lambda_{\text {em }}\left(c_{\mathrm{NP}}^{9}\right)=447 \mathrm{~nm}$. Dependences of intensities $I_{\mathrm{em}}$ of the PL emission peaks \#1 and \#2 have maxima $\mathrm{I}_{\mathrm{em}}^{1}\left(\mathrm{c}_{\mathrm{NP}}^{4}\right)=122$ a.u. for $\mathrm{c}_{\mathrm{NP}}^{4}=1.25 \mathrm{mg} / \mathrm{mL}$ at $\lambda_{\mathrm{em}}^{1}=527$ $\mathrm{nm}$ and $I_{\mathrm{em}}^{2}\left(c_{\mathrm{NP}}^{6}\right)=600$ a.u. for $c_{\mathrm{NP}}^{6}=0.31 \mathrm{mg} / \mathrm{mL}$ at $\lambda_{\mathrm{em}}^{2}=452$ $\mathrm{nm}$, respectively. The ratio $I_{\mathrm{em}}^{1}\left(c_{\mathrm{NP}}^{4}\right) / I_{\mathrm{em}}^{1}\left(c_{\text {init }}\right)=6.3$ for peak \#1 and the ratio $I_{\mathrm{em}}^{2}\left(\mathrm{c}_{\mathrm{NP}}^{6}\right) / I_{\mathrm{em}}^{2}\left(c_{\text {init }}\right)=30.5$ for peak $\# 2$ were obtained.

The PL response/intensity is proportional to the $c_{\mathrm{NP}}^{\mathrm{x}}$ for a small concentration of carbon NPs: $c_{\mathrm{NP}}^{\mathrm{x}} \leq c_{\text {init }} / 2^{4}=c_{\text {peak\#1 } 1}^{\max }$ and $c_{\mathrm{NP}}^{\mathrm{x}} \leq c_{\text {init }} / 2^{6}=c_{\text {peak } \# 2}^{\max }$. Increasing the concentration of carbon NPs above $c_{\text {peak } \# 1,2}^{\max }$ caused a decrease in the PL intensity due to concentration quenching and fluorescence resonance energy transfer. $^{31}$
PL analysis methods are highly sensitive to the presenting analytes $^{32}$ since the variance of the PL intensity, change in the shape of spectra, and new spectral features of luminescent probes are observed in their presence. ${ }^{33}$ The colloid solution with concentration $c_{\mathrm{NP}}^{4}=20 / 2^{4} \mathrm{mg} / \mathrm{mL}$ was chosen for further sensor investigation and application. The solution spectra show the presence of clearly defined features, whose shape and intensity can be affected with investigated analytes: armagnac, cognac, whiskey, and the reference mixture of ethanol/water $(40 \% / 60 \%)$. From the end-user point of view, the individual taste of considered beverages can be defined with aromatic components $^{34}$ contributed with the grape (primary aroma), winemaking (fermentation aroma), distillation (aroma produced by the heating process), and aging (aroma produced with storage vessels as oak barrels).

3D PL maps were constructed from the dependence of the intensity of PL emission against wavelengths for the solution of NPs $\left(c_{\mathrm{NP}}^{4}=20 / 2^{4} \mathrm{mg} / \mathrm{mL}\right)$ in the presence of analytes (Figure $4)$. These maps were considered as the response of the sensor system based on the solution of carbon NPs. For better visual distinguishing, contour lines at the same intensity levels were depicted on each PL map (Figure $4 a-c$ ). Vertical large dotted lines depict the position of maxima of the PL emission spectrum at the fixed excitation wavelength. Horizontal small dotted lines mark the position of the local maxima of the excitation spectrum. Each subplot in Figure 4 shows the 
presence of two emission peaks: peak \#1 at $\lambda_{\mathrm{em}}^{1}\left(\lambda_{\mathrm{ex}}^{1}=355 \mathrm{~nm}\right)$ $=465 \mathrm{~nm}$ and peak \#2 at $\lambda_{\mathrm{em}}^{2}\left(\lambda_{\mathrm{ex}}^{2}=285 \mathrm{~nm}\right)=527 \mathrm{~nm}$. The intensity and shape of the global and local maxima/minima are different for each considered analyte. This difference allows us to distinguish analytes, so the prepared carbon NPs are prominent nanomaterials for sensing applications. The $\mathrm{pH}$ value for the solutions containing carbon NPs have an effect on the PL intensity within the range of "the alcohol pHs." In the range from 15 to $25{ }^{\circ} \mathrm{C}$, the solutions of carbon NPs in aqueous/alcohol solvents are stable for months (Table S1, Figure S8, Supporting Information). The changes in the PL intensity with so-called $\mathrm{pHs}$ "in the $\mathrm{pH}$ range of studied alcohol beverage solutions" are minimal.

To ensure a high discrimination capability level of the proposed approach, the PL data can be treated with use of the PCA method. ${ }^{26,27}$ This multivariate analysis approach enables to find a set of linearly uncorrelated variables so that the first (PC1) has maximum variance, and each next variable (PC2 and PC3) is orthogonal to the previous and has maximum possible variance with this constraint. This method is widely used for dimension reduction because most of the information is concentrated in the first component and commonly employed in various combinatorial platforms for discrimination purposes.

As a result, Figure 5 shows a plot of three first principal components containing clouds of points for each of the tested

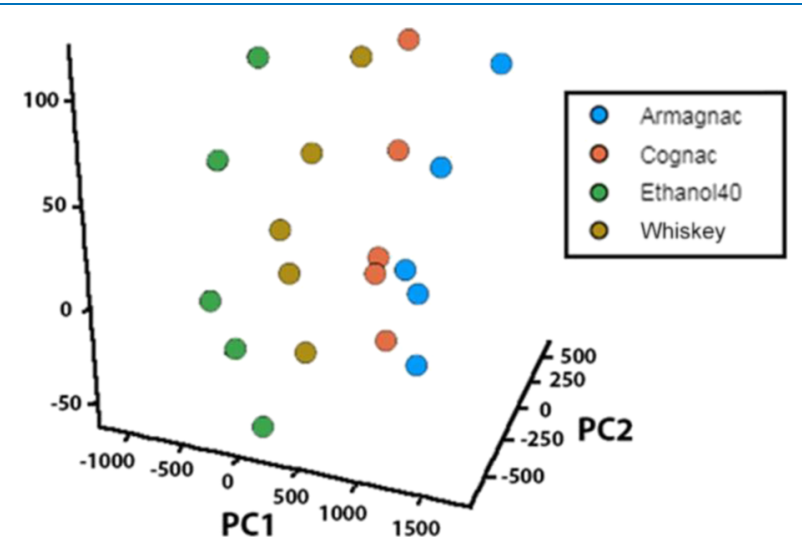

Figure 5. PCA visualization of the components from the analysis of PL map as the response of sensor system with carbon NPs on the presence of analytes: armagnac, cognac, whiskey, and ethanol/water (40\%/60\%) mixture.

alcohols. In particular, because the distance between the points reflects their nonsimilarity, clear clustering of the data illustrates a perfect degree of discrimination capability of our sensing system to recognize among the studied spirit drinks.

Each subplot in Figure 5 could be a pattern of the response of the sensor system in the presence of a certain analyte. The points of subplots in Figure 5 are the response of individual elementary sensors that form a $2 \mathrm{D}$ sensor matrix considered as "electronic tongue." ${ }^{\text {35,36 }}$ Each point in Figure 5 represents the result of PCA transformation of PL maps of analytes as input data (subplots of Figure 5). Five series of measurements of PL maps (an analyte pattern) for each analyte were carried out on different days using freshly prepared solutions with NPs. The proposed sensor system based on carbon NPs with the PL measurement method shows good repeatability and reproducibility of the measurement results.
As can be seen in Figure 5, the PCA demonstrates that the result points for each analyte are not formed by overlapped clusters in the principal components space. According to the presented data, the PCA of the analytes, armagnac, cognac, whiskey, are clearly distinguished both from each other and from the reference mixture of ethanol and water (Ethanol40). This means that the impact of aroma molecules of concrete beverage (analyte) on the PL properties of the carbon NPs is specific for considered analytes. The observed phenomenon is found as the solid ground for the creation of sensor systems based on the carbon NPs. The location of the whiskey cluster is closer to the Ethanol40 cluster as compared to those of the cognac and armagnac clusters. These clusters are close to one another that discloses the affinity of these beverages.

To explain the dependence of the recorded PL spectra on the type of alcoholic beverage, we should consider the PL mechanisms of carbon NPs. Unfortunately, to date, there is no unambiguously accepted model describing the emission spectra of carbon NPs. Carbon NPs can perform two, three, or more emission bands under one-wavelength excitation depending on the synthesis protocol, organic carbon source as the precursor, and doping. ${ }^{37}$ The emission bands can be determined by different emission centers and surface states of the NPs. ${ }^{38}$ Different peaks can be related to excitonic states, ${ }^{39}$ graphenol-related structure, ${ }^{40}$ combination of intrinsic $\left(\mathrm{sp}^{2}\right.$ graphite structures) and defect transitions ( $\mathrm{sp}^{3}$ matrix), oxygen-containing groups or aromatic structures, ${ }^{42}$ and others.

The effect of various substances on the PL of NPs is discussed in a number of works. The most important NP application is the sensors since the fluorescence of NPs can be quenched, for example, by heavy metal ions such as $\mathrm{Fe}^{3+}, \mathrm{Cu}^{2+}$, $\mathrm{Fe}^{2+}, \mathrm{Ag}^{+}, \mathrm{Cr}^{6+}, \mathrm{Au}^{3+}$, and $\mathrm{Hg}^{2+} \cdot{ }^{43,44}$ As trapping of the photoinduced charge carriers can suppress the luminescence signal, it can be controlled by the electron-donating capacity of the surrounding molecules. The electron donor species can stabilize the holes on the surface. ${ }^{45,46}$ Methanol is an electron donor, and being a smaller molecule than the other tested solvents, it can easily penetrate the functional groups surrounding the NPs for direct electron donation to the core and/or surface states, which leads to PL quenching. ${ }^{47}$ The dissociated tannic acid unit with approximately four negative charges has the capacity to facilitate the electron transfer process from the photoexcited NPs to the aromatic groups in tannic acid, thus enhancing the nonradiative transition of NPs and inducing a high fluorescence quenching efficiency. ${ }^{48}$

From the other side, the surface passivation of NPs can decrease the surface defects and increase the exciton-hole recombination probability, which will prevent NPs from agglomeration and enhance their emission intensity. Surface passivation includes both capping bare NPs with some longchain agents and oxidizing the surfaces of NPs with strong acids. ${ }^{42}$ Due to the usual presence of long-chain carboxylic acids and some other functional substances in carbon sources, carbonization and passivation can occur at the same time during the synthetic process of NPs. As a result, NPs synthesized are often self-passivated. Their surfaces are enriched with hydroxyl, amine, carboxyl, or thiol groups. ${ }^{49}$ The surface passivation by different organic solvents can form different surface defects on the surface of NPs and can introduce different emission sites upon NPs, leading to the changes in the peak position and intensities of the emission spectrum of NPs. ${ }^{50}$ It was shown that the emission peak positions for hydrothermal NPs varied from 440 to $625 \mathrm{~nm}^{51}$ 
and that the emission wavelength was red-shifted as the degrees of surface oxidation increased.

Thus, the PL of carbon NPs in such complex liquids as alcohol drinks is influenced simultaneously by several factors considered since different components of these beverages act in different ways, increasing/decreasing the quantum yield of individual PL bands and shifting the band maxima. Since the considered alcoholic beverages of cognac, whiskey, armagnac, and ethanol/water mixture have different additive compositions, this determines the possibility of recognizing these liquids by the PL method.

\section{CONCLUSIONS}

A simple method for sensitive and selective quality detection and recognition of armagnac, cognac, and whiskey was developed with photoluminescent carbon NPs. In the presence of the alcoholic beverages and a reference mixture of ethanol and water, the PL maps of carbon NPs are clearly distinguished. This means that the impact of aroma molecules and other additives in a target beverage on the PL properties of carbon NPs is specific for the considered analytes; this phenomenon can be the base for the elaboration of sensor systems. The proposed sensor system based on carbon NPs and PL measurement method showed good repeatability and reproducibility of results to recognize alcoholic beverages of different chemical compositions.

\section{EXPERIMENTAL SECTION}

Synthesis. Carbon NPs were prepared from the mixture of urea (p.a. grade) and anhydrous citric acid (pharm. grade) taken in a molar ratio of 2 to 1 . The total mass of the mixture was $10 \mathrm{~g}$. After mixing, the components were transferred in an open $100 \mathrm{~mL}$ reactor of Pyrex glass. This reactor was placed in a shaft furnace whose temperature was increased to $135{ }^{\circ} \mathrm{C}$ for $15 \mathrm{~min}$. The reaction mixture was melted and colored yellow. After that, the reactor temperature was raised to $165{ }^{\circ} \mathrm{C}$ and held at this temperature for $1 \mathrm{~h}$. At the end of the carbonization process, the evolution of gases or vapors was not observed and the melt transformed into a brown-black shiny fragile mass. This carbonized mass was dissolved in $80 \mathrm{ml}$ of $15 \%$ isopropanol under slight heating and acidified with 10 $\mathrm{ml}$ of $30 \% \mathrm{HCl}$. The resulting precipitate was filtered and then dried in air. From the fine black powder of carbon NPs, the solution of NPs was prepared and used as a sensor system.

Characterization. TGA of carbon NPs was carried out in an argon gas flow with a custom TGA instrument. ${ }^{52}$ FTIR ATR spectrum was recorded with an IR Prestige-21 spectrometer (Shimadzu) equipped with a MIRacle ATR accessory (PIKE Technologies) with a $\mathrm{ZnSe}$ crystal for the sample contact. ${ }^{1} \mathrm{H}$ NMR spectrum was recorded at $400 \mathrm{MHz}$ on a Varian Mercury 400 spectrometer with tetramethylsilane as an internal standard in DMSO- $d_{6}$. Raman spectrum of carbon NPs was collected in the backscattered mode with a HORIBA Jobin Yvon-LabRAM ARAMIS integrated confocal micro-Raman system equipped with a microscope (BX41, Olympus, Japan) and a diode-pumped solid-state laser. ${ }^{53} \mathrm{~A}$ $633 \mathrm{~nm}$ laser was focused by an Olympus $100 \times$ objective lens (UPLSAPO, NA $=0.95$ ) on the sample placed in an open-air environment at room temperature. The excited Raman scattering signal was collected by a Labram ARAMIS (JobinYvon) spectrometer. TEM images were captured on an electronic microscope (JEOL JEM-2100F, $200 \mathrm{kV}$ ). XPS spectra were recorded with a Kratos Axis Ultra X-ray photoelectron spectrometer employing $\mathrm{Mg} \mathrm{K} \alpha$ X-rays. Optical properties of the alcohol solutions of carbon NPs were examined by a Shimadzu UV 2700 instrument.

Setup for PL measurements

PL measurements were carried out using a Cary Eclipse fluorescence spectrophotometer equipped with a Xenon lamp as the excitation source. ${ }^{54}$ We used a classic measurement scheme with a perpendicular arrangement of the excitation beam and excitation spectra propagation relatively cuvette with a solution with carbon NPs. The PL spectra and PL against PL maps were recorded for excitation wavelengths in the range of 250-380 $\mathrm{nm}$. Emission spectra lie in the range of 400-800 $\mathrm{nm}$. Parameters of the PL measurements are the excitation filter range of $250-395 \mathrm{~nm}$, the emission filter range of 360$1100 \mathrm{~nm}$, and an averaging time of $0.1 \mathrm{~s}$. Quartz cuvettes with a volume of $2 \mathrm{~mL}$ were used for all experiments.

Alcohol beverages with the same ethanol-to-water volume ratio $(40 \% / 60 \%)$, whiskey (William Peel), cognac (Courcel), and armagnac (Saint-Vivant), were investigated as analytes. Each of the analytes has a distinct chemical composition determined by manufacturing technology and aging. A mixture of ethanol and water $(40 \% / 60 \%)$ was used as a reference solution. In such a way, we exclude the ethanol factor in exploring the effect of beverage-specific components on the sensor system based on carbon NPs.

\section{ASSOCIATED CONTENT}

\section{Supporting Information}

The Supporting Information is available free of charge at https://pubs.acs.org/doi/10.1021/acsomega.1c01953.

Characterization of carbon NPs by TG/differential TG analyses, ${ }^{1} \mathrm{H}$ NMR, XPS, FTIR ATR, and Raman and absorbance spectra; dependences of the intensity of PL emission spectra on the excitation spectra for different concentrations of carbon NPs; and PL intensity at the excitation wavelength $365 \mathrm{~nm}$ against $\mathrm{pH}$ and temperature and storage time (PDF)

\section{AUTHOR INFORMATION}

\section{Corresponding Author}

Valeriy A. Skryshevsky - Institute of High Technologies, Taras Shevchenko National University of Kyiv, Kyiv 01601, Ukraine; Corporation Science Park Taras Shevchenko

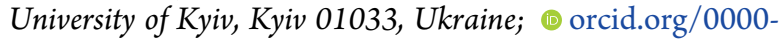
0003-0249-5556; Email: skrysh@univ.kiev.ua

\section{Authors}

Ivan I. Ivanov - Institute of High Technologies, Taras Shevchenko National University of Kyiv, Kyiv 01601, Ukraine; Corporation Science Park Taras Shevchenko University of Kyiv, Kyiv 01033, Ukraine

Alexander N. Zaderko - Institute of High Technologies, Taras Shevchenko National University of Kyiv, Kyiv 01601, Ukraine; Corporation Science Park Taras Shevchenko University of Kyiv, Kyiv 01033, Ukraine; 이이이.org/00000002-8174-1470

Vladimir Lysenko - Light-Matter Institute (ILM), UMR5306, University of Lyon (UCBL), Villeurbanne 69622, France

Thierry Clopeau - Institut Camille Jordan, UMR-5208, University of Lyon (UCBL), Villeurbanne 69622, France 
Vladyslav V. Lisnyak - Faculty of Chemistry, Taras Shevchenko National University of Kyiv, Kyiv 01601, Ukraine; Prěsov University in Prěsov, Prěsov 08001, Slovakia

Complete contact information is available at:

https://pubs.acs.org/10.1021/acsomega.1c01953

\section{Author Contributions}

The manuscript was written through the contributions of all coauthors. All authors have approved the final version of the manuscript.

\section{Notes}

The authors declare no competing financial interest.

\section{ACKNOWLEDGMENTS}

This work was partially supported by the EU Horizon 2020 Research and Innovation Staff Exchange Programme (RISE) under the Marie Skłodowska-Curie Action (project 101008159 "UNAT").

\section{REFERENCES}

(1) Han, J.; Li, Z.; Shi, P.; Li, F.; Duan, Y.; Han, T. A Chemosensor for Fingerprinting Liquors: Implication for Differentiation and Identification. Sens. Actuators, B 2017, 248, 101-107.

(2) Li, Z.; Suslick, K. S. A Hand-Held Optoelectronic Nose for the Identification of Liquorsfication of Liquors. ACS Sens. 2018, 3, 121127.

(3) Ledauphin, J.; Le Milbeau, C.; Barillier, D.; Hennequin, D. Differences in the Volatile Compositions of French Labeled Brandies (Armagnac, Calvados, Cognac, and Mirabelle) Using GC-MS and PlsDa. J. Agric. Food Chem. 2010, 58, 7782-7793.

(4) Schreier, P.; Drawert, F.; Winkler, F. Composition of neutral volatile constituents in grape brandies. J. Agric. Food Chem. 1979, 27, 365-372.

(5) Janacova, A.; Sadecka, J.; Kohajdova, Z.; Spanik, I. The identification of aroma-active compounds in Slovak brandies using GC-sniffing, GC-MS and sensory evaluation. Chromatographia 2008, $67,113-121$.

(6) Ledauphin, J.; Guichard, H.; Saint-Clair, J.-F.; Picoche, B.; Barillier, D. Chemical and Sensorial Aroma Characterization of Freshly Distilled Calvados. 2. Identification of Volatile Compounds and Key Odorants. J. Agric. Food Chem. 2003, 51, 433-442.

(7) Rodríguez Madrera, R.; Suárez Valles, B.; García Hevia, A.; Fernandez, O.; Fernández Tascón, N.; Mangas Alonso, J. J. Production and composition of cider spirits distilled in "alquitara". J. Agric. Food Chem. 2006, 54, 9992-9997.

(8) Nickles, J. Certified Specialist of Spirits Study Guide; Society of Wine Educators: Washington, 2015.

(9) Jeffery, J. D. E. Aging of Whiskey Spirits in Barrels of NonTraditional Volume. Master's Thesis; Michigan State University, 2012

(10) Xu, M. L.; Yu, Y.; Ramaswamy, H. S.; Zhu, S. M. Characterization of Chinese Liquor Aroma Components During Aging Process and Liquor Age Discrimination Using Gas Chromatography Combined with Multivariable Statistics. Sci. Rep. 2017, 7, 39671.

(11) Kew, W.; Goodall, I.; Clarke, D.; Uhrín, D. Chemical Diversity and Complexity of Scotch Whisky as Revealed by High-Resolution Mass Spectrometry. J. Am. Soc. Mass Spectrom. 2017, 28, 200-213.

(12) Martins, A. R.; Talhavini, M.; Vieira, M. L.; Zacca, J. J.; Braga, J. W. B. Discrimination of whisky brands and counterfeit identification by UV-Vis spectroscopy and multivariate data analysis. Food Chem. 2017, 229, 142-151.

(13) Ivanov, I. I.; Klyui, N. I.; Skryshevsky, V. A. Colorimetric analysis of optical reflection from thin porous silicon for detection of organic liquids. Sens. Actuators, B 2019, 280, 102-108.
(14) Skryshevsky, V. A.; Vikulov, V. A.; Tretiak, O. V.; Zinchuk, V. M.; Koch, F.; Dittrich, T. Electrical characterization of gas sensing devices based on porous $\mathrm{TiO}_{2}$. Phys. Status Solidi A 2003, 197, 534538

(15) Hamerly, T.; Bothner, B. Adding Analytical Metrics to the Production and Aging of Whiskey Using a Protein Sensor Assay. Mass Spectrom Purif Tech 2016, 02. DOI: 10.4172/2469-9861.1000111.

(16) Demyttenaere, J.; Sanchezmartinez, J.; Verhé, R.; Sandra, P.; Dekimpe, N. Analysis of volatiles of malt whisky by solid-phase microextraction and stir bar sorptive extraction. J. Chromatogr. A 2003, 985, 221-232.

(17) Han, J.; Ma, C.; Wang, B.; Bender, M.; Bojanowski, M.; Hergert, M.; Seehafer, K.; Herrmann, A.; Bunz, U. H. F. A Hypothesis-Free Sensor Array Discriminates Whiskies for Brand, Age, and Taste. Chem 2017, 2, 817-824.

(18) Macias, G.; Sperling, J. R.; Peveler, W. J.; Burley, G. A.; Neale, S. L.; Clark, A. W.; Clark Alasdair, W. Whisky Tasting Using A Bimetallic Nanoplasmonic Tongue. Nanoscale 2019, 11, 1521615223.

(19) Demchenko, A. P. Introduction to Fluorescence Sensing; Springer International Publisher, 2015.

(20) Yi, Y.; Zhu, G.; Liu, C.; Huang, Y.; Zhang, Y.; Li, H.; Zhao, J.; Yao, S. A Label-Free Silicon Quantum Dots-Based Photoluminescence Sensor for Ultrasensitive Detection of Pesticides. Anal. Chem. 2013, 85, 11464-11470.

(21) Zhang, X.; Xu, N.-Y.; Ruan, Q.; Lu, D.-Q.; Yang, Y.-H.; Hu, R. A label-free and sensitive photoluminescence sensing platform based on long persistent luminescence nanoparticles for the determination of antibiotics and 2,4,6-trinitrophenol. RSC Adv. 2018, 8, 5714.

(22) Syshchyk, O.; Skryshevsky, V. A.; Soldatkin, O. O.; Soldatkin, A. P. Enzyme biosensor systems based on porous silicon photoluminescence for detection of glucose, urea and heavy metals. Biosens. Bioelectron. 2015, 66, 89-94.

(23) Sun, X.; Lei, Y. Fluorescent carbon dots and their sensing applications. Anal. Chem. 2017, 89, 163-180.

(24) Lim, S. Y.; Shen, W.; Gao, Z. Carbon quantum dots and their applications. Chem. Soc. Rev. 2015, 44, 362-381.

(25) Zhu, S.; Song, Y.; Zhao, X.; Shao, J.; Zhang, J.; Yang, B. The photoluminescence mechanism in carbon dots (graphene quantum dots, carbon nanodots, and polymer dots): current state and future perspective. Nano Res. 2015, 8, 355-381.

(26) Cross, R. Principal Component Analysis Handbook; Clanrye International, 2015.

(27) Beebe, K. R.; Pell, R. J.; Seasholtz, M. B. Chemometrics: A Practical Guide; Wiley: New York, 1998.

(28) Kasprzyk, V.; Świergosz, T.; Bednarz, S.; Walas, K.; Bashmakovac, N.; Bogdała, D. Luminescence phenomena of carbon dots derived from citric acid and urea - a molecular insight. Nanoscale 2018, 209, 13889-13894.

(29) Zholobak, N. M.; Popov, A. L.; Shcherbakov, A. B.; Popova, N. R.; Guzyk, M. M.; Antonovich, V. P.; Yegorova, A. V.; Scrypynets, Y. V.; Leonenko, I. I.; Baranchikov, A. Y.; Ivanov, V. K. Facile fabrication of luminescent organic dots by thermolysis of citric acid in urea melt, and their use for cell staining and polyelectrolyte microcapsule labelling. Beilstein J. Nanotechnol. 2016, 7, 1905-1917.

(30) Huang, X.; Li, Y.; Zhong, X.; Rider, A. E.; Ostrikov, K. K. Fast Microplasma Synthesis of Blue Luminescent Carbon Quantum Dots at Ambient Conditions. Plasma Processes Polym. 2015, 12, 59-65.

(31) Sauer, M.; Hofkens, J.; Enderlein, J. Handbook of Fluorescence Spectroscopy and Imaging: From Single Molecules to Ensembles; Wiley, 2011.

(32) Lakowicz, J. R. Principles of Fluorescence Spectroscopy; Springer, 2006.

(33) Yu, L.; Wang, S.; Huang, K.; Liu, Z.; Gao, F.; Zeng, W. Fluorescent probes for dual and multi analyte detection. Tetrahedron 2015, 71, 4679-4706.

(34) Caballero, B.; Finglas, P.; Toldra, F. Encyclopedia of Food Sciences and Nutrition, Brandy and Cognac; Academic Press, 2006. 
(35) Litvinenko, S. V.; Bielobrov, D.; Lysenko, V.; Nychyporuk, T.; Skryshevsky, V. A. Might silicon surface be used for electronic tongue application? ACS Appl. Mater. Interfaces 2014, 6, 18440-18444.

(36) Oliinyk, B. V.; Isaieva, K.; Manilov, A. I.; Nychyporuk, T.; Geloen, A.; Joffre, F.; Skryshevsky, V. A.; Litvinenko, S. V.; Lysenko, V.; Vladimir, L. Silicon-Based Optoelectronic Tongue for Label-Free and Nonspecific Recognition of Vegetable Oils. ACS Omega 2020, 5, 5638-5642.

(37) Zhu, P.; Tan, K.; Chen, Q.; Xiong, J.; Gao, L. Origins of Efficient Multiemission Luminescence in Carbon Dots. Chem. Mater. 2019, 31, 4732-4742.

(38) Mohan, R.; Drbohlavova, J.; Hubalek, J. Dual Band Emission in Carbon Dots. Chem. Phys. Lett. 2018, 692, 196-201.

(39) Feng, T.; Zeng, Q.; Lu, S.; Yan, X.; Liu, J.; Tao, S.; Yang, M.; Yang, B. Color-Tunable Carbon Dots Possessing Solid-State Emission for Full-Color Light-Emitting Diodes Applications. ACS Photonics 2018, 5, 502-510.

(40) Zhang, W.; Wang, Y.; Liu, X.; Meng, X.; Xu, H.; Xu, Y.; Liu, B.; Fang, X.; Li, H.-B.; Ding, T. Insight into the Multiple Quasi-molecular States in Ethylenediamine Reduced Graphene Nanodots. Phys. Chem. Chem. Phys. 2017, 19, 28653-28665.

(41) Zhang, T.; Zhu, J.; Zhai, Y.; Wang, H.; Bai, X.; Dong, B.; Wang, H.; Song, H. A Novel Mechanism for Red Emission Carbon Dots: Hydrogen Bond Dominated Molecular States Emission. Nanoscale 2017, 9, 13042-13051.

(42) Kang, C.; Huang, Y.; Yang, H.; Yan, X. F.; Chen, Z. P. A Review of Carbon Dots Produced from Biomass Wastes. Nanomaterials 2020, 10, 2316.

(43) El-Shafey, A. M.; Asmaa, M. Carbon dots: Discovery, structure, fluorescent properties, and applications. Green Process. Synth. 2021, 10, 134-156.

(44) Pan, M.; Xie, X.; Liu, K.; Yang, J.; Hong, L.; Wang, S. Fluorescent Carbon Quantum Dots-Synthesis, Functionalization and Sensing Application in Food Analysis. Nanomaterials 2020, 10, 930.

(45) Wang, X.; Cao, L.; Lu, F.; Meziani, M. J.; Li, H.; Qi, G.; Zhou, B.; Harruff, B. A.; Kermarrec, F.; Sun, Y.-P. Photoinduced electron transfers with carbon dots. Chem. Commun. 2009, 25, 3774-3776.

(46) Sotelo-Gonzalez, E.; Coto-Garcia, A. M.; Fernandez-Argüelles, M. T.; Costa-Fernandez, J. M.; Sanz-Medel, A. Immobilization of phosphorescent quantum dots in a sol-gel matrix for acetone sensing. Sens. Actuators, B 2012, 174, 102-108.

(47) Latha, M.; Aruna-Devi, R.; Bogireddy, N. K. R.; Rios, S. E. S.; Mochan, W. L.; Castrellon-Uribe, J.; Agarwal, V. N-doped oxidized carbon dots for methanol sensing in alcoholic beverages. RSC Adv. 2020, 10, 22522-22532.

(48) Yang, P.; Zhu, Z.; Chen, M.; Zhou, X.; Chen, W. Microwaveassisted synthesis of polyamine-functionalized carbon dots from xylan and their use for the detection of tannic acid. Spectrochim. Acta, Part A 2019, 213, 301-308.

(49) Varisco, M.; Zufferey, D.; Ruggi, A.; Zhang, Y.; Erni, R.; Mamula, O. Synthesis of hydrophilic and hydrophobic carbon quantum dots from waste of wine fermentation. $R$. Soc. Open Sci. 2017, 4, 170900-170911.

(50) Zhang, R.; Liu, Y.; Yu, L.; Li, Z.; Sun, S. Preparation of highquality biocompatible carbon dots by extraction, with new thoughts on the luminescence mechanisms. Nanotechnology 2013, 24, 225601225610.

(51) Ding, H.; Yu, S.-B.; Wei, J.-S.; Xiong, H.-M. Full-color lightemitting carbon dots with a surface-state-controlled luminescence mechanism. ACS Nano 2016, 10, 484-491.

(52) Tsapyuk, G. G.; Diyuk, V. E.; Mariychuk, R.; Panova, A. N.; Loginova, O. B.; Grishchenko, L. M.; Dyachenko, A. G.; Linnik, R. P.; Zaderko, A. N.; Lisnyak, V. V. Effect of ultrasonic treatment on the thermal oxidation of detonation nanodiamonds. Appl. Nanosci. 2020, 10, 4991-5001.

(53) Lisnyak, V. V.; Zaderko, A. N.; Mariychuk, R.; Lysenko, V.; Boldyrieva, O. Y.; Skryshevsky, V. A.; Mussabek, G.; Taurbayev, Y.; Zhylkybayeva, N.; Tananiko, O. Y. Preparation and characterization of
F-, O-, and N-containing carbon nanoparticles for $\mathrm{pH}$ sensing. Appl. Nanosci. 2021, DOI: 10.1007/s13204-021-01725-7.

(54) Agilent Cary Eclipse Fluorescence Spectrophotometer, 2019. Agilent Technologies, Inc. https://www.agilent.com/cs/library/ brochures/5990-7788EN_Cary_Eclipse_Brochure.pdf 